\title{
What's Congress Doing on Twitter?
}

\author{
Libby Hemphill, Jahna Otterbacher, and Matthew A. Shapiro \\ Illinois Institute of Technology \\ 3301 S Dearborn St, Chicago IL, 60616 \\ \{libby.hemphill, jahna.otterbacher, mshapir2\}@iit.edu
}

\begin{abstract}
As Twitter becomes a more common means for officials to communicate with their constituents, it becomes more important that we understand how officials use these communication tools. Using data from 380 members of Congress' Twitter activity during the winter of 2012, we find that officials frequently use Twitter to advertise their political positions and to provide information but rarely to request political action from their constituents or to recognize the good work of others. We highlight a number of differences in communication frequency between men and women, Senators and Representatives, Republicans and Democrats. We provide groundwork for future research examining the behavior of public officials online and testing the predictive power of officials' social media behavior.
\end{abstract}

\section{CATEGORIES AND SUBJECT DESCRIPTORS}

\section{K.4.1 [Computers and Society]: Public Policy Issues}

\section{KEYWORDS}

Congress; Twitter; social media; political communication; automated classification

\section{INTRODUCTION}

As of March 2012, members of the U.S. House of Representatives had 407 active, verifiable Twitter accounts, while members of the U.S. Senate had 97. Those 504 accounts, and the thousands more who respond to them, generate thousands of tweets per day. Given this level of activity, it's natural to ask, what are they doing on Twitter? And how does their tweeting matter?

Twitter has garnered public attention for its use in a number of socio-political events such as social demonstrations [16], presidential debates [14, 48], and campaigning [37]. Earlier studies of political communication in social media explored the content of tweets from Congress [20], connections among political blogs [1], and political position among candidates for public office [37]. Because Twitter is relatively new, the landscape of Congressional communication (compared to print media and the

Permission to make digital or hard copies of all or part of this work for personal or classroom use is granted without fee provided that copies are not made or distributed for profit or commercial advantage and that copies bear this notice and the full citation on the first page. To copy otherwise, or republish, to post on servers or to redistribute to lists, requires prior specific permission and/or a fee. CSCW'13, February 23-27, 2013, San Antonio, Texas, USA. Copyright 2013 ACM 978-1-4503-1331-5/13/02 ...\$15.00.
Congressional Record, for instance) has only recently become mature enough to study. Few systematic studies of how public officials use this new method of communicating with the public exist, and we contribute to that body of literature by providing detailed understanding of how public officials use social media. We also contribute to literature on social media- research methods by demonstrating successful approaches to automatic classification of social media content.

Our findings suggest that officials frequently use Twitter to advertise their political positions and to provide information but rarely to request political action from their constituents or to recognize the good work of others. Rules governing public officials' social media and web presences are evolving ${ }^{1}$, and our analysis reveals the conventions developing through officials' regular use of Twitter.

\section{RELATED LITERATURE}

Most of the existing research on Congress's use of internet and social media communication focuses on elections and campaigning [15, 21, 24, 47, 50, 54]. Candidates' websites, for instance, have received a great deal of attention, as they provide information about the candidate and his or her positions and often encourage individuals to either volunteer or donate to the campaign [50]. While managing their own websites provides a great deal of freedom for candidates, the candidates limit the number of issues they present there, and they engage their opponents on only a few issues most salient to the public [15]. Incumbents provide more information about their policy positions than their opponents, and all candidates tend to engage in "position taking" more often than "issue dialogue" [54].

Together, these findings suggest that candidates use their websites to promote themselves rather than to engage their opponents or their constituents. Their disagreements with opponents are implicit in these "position taking" statements where they outline their own views without referencing their opponents. These patterns of engagement with opponents and interactions with constituents represent departures from offline political communication [54].

1 For instance, see the Committee on House Administration's Regulations governing official Social Media and Secondary web site content: http://democrats.cha.house.gov/official-social-media-andsecondary-web-sites 
Research on online political communication dramatically increased following the 2004 elections in the U.S., when candidates' websites received a great deal of attention. Since then, social media outlets such as Twitter and Facebook have received more attention from politicians, voters, and researchers in both the U.S. and abroad. Recent examinations of Twitter's role in recent elections in Brazil [18] and Iran [16], for instance, found that the impact in Iran's elections remains unclear [16], while a strong social media presence provided an edge for candidates in Brazil's lower house of Congress [18].

Beyond election campaigns, researchers are beginning to examine the role of social media in every day communication [32] and in policy debates [28, 33]. Recent results indicate that Korean officials use Twitter to communicate with one another rather than with their constituents [29], and we found similar patterns of communication among U.S. officials.

Much of the popular press coverage of social media use for political communication centers around transparency and increasing officials' accountability [45, 49] or the fleeting nature of social media content [17]. Officials' strategies for employing social media are evolving, but it's becoming clear that allowing MOCs to communicate directly with their constituents impacts political parties' efforts to present a consistent brand [23].

Though candidates' websites are now well understood, existing literature does not adequately explain how the U.S. Congress is using Twitter, whether that use differs from their approaches to more permanent communication platforms like print media, or whether Congress' Twitter use marks an increase in responsiveness or transparency. Golbeck and colleagues [20] provided the first overview of MOCs' Twitter use, finding that Congress used Twitter mostly to distribute information, especially to link to other sources such as their blogs. The behaviors Golbeck and colleagues identified, though, did not suggest that Congress was providing increased government transparency or responsiveness through their use.

Austin [2] proposed that communication between humans is often much more than a means to transfer information from a speaker to a hearer. We are often trying to achieve a particular goal when we speak, and these underlying actions are referred to as being speech acts [3]. Similarly, a question of particular interest in our work is what an official achieves (or tries to achieve) when he or she posts a given tweet. In other words, we can approach the analysis of officials' tweets using the concept of the speech act.

We provide an expanded and detailed account of the speech acts members of Congress (MOCs) make via Twitter and discuss the implications of their social media behavior for online political engagement more broadly.

\section{METHODS}

\section{Data Collection}

We first identified verifiable Twitter accounts for members of Congress, then collected their tweets for a period of time and qualitatively coded a subset of tweets for actions that officials performed through posting the tweet. Using the Twitter Database Server [22] and Twitter-collectors [25], we gathered three sets of tweets between August 2011 and February 2012. First, we gathered a subset of 791 total tweets from the top 10 and bottom 10 users in each of three categories: tweets, followers, and friends. We used that subset of extreme users' tweets to gather a diverse set of tweets accomplishing a number of different actions in order to develop our coding scheme for "Action" (described in detail in the next section). We expected behaviors among the most and least active users to differ enough to provide a more diverse sample than a simple random sampling method could guarantee.

Then, we gathered another subset of 526 tweets from all active public officials with which to check our coding scheme and to train the automated classifier. Once we developed a robust classifier, we gathered 30,373 original tweets posted by 380 elected Congressmen between December 22, 2011 and February 29, 2012. This analysis is part of an ongoing project to examine the relationships among Twitter conversations and offline political behavior, and only those officials who mentioned or were mentioned by another official during the data collection period are included in this last dataset. The 30,373 tweets include all tweets, except explicit retweets, posted by those 380 officials who mentioned or were mentioned by others during that time period.

\section{Coding for Action}

When manually coding the subset of 791 tweets described above, we excluded retweets and duplicate tweets. We used three rounds of inductive coding to develop a robust coding scheme for the action taken in tweets. The resulting scheme used six codes - narrating, positioning, directing to information, requesting action, giving thanks, and other to categorize the kind of action taken in a tweet. Codes were not mutually exclusive, meaning a tweet could be coded as exhibiting more than one action. For example, "With massive debt, why are taxpayers funding wine tasting? Washington's spending addiction continues http://t.co/2QaYJmo," a tweet from Jim DeMint, was coded as both positioning and directing to information. It's clear that DeMint disagrees with this use of public funds (i.e., positioning), and he also suggests that his followers examine the article at the link provided for more information. Cohen's kappa [13] scores for each code show reliable $(>=0.70)$ inter-coder agreement [34]. The code definitions, examples, and kappas are reported in Table 1. Positioning and directing to information were by far the most common actions exhibited on Twitter. 


\begin{tabular}{|c|c|c|c|c|}
\hline Code & Definition & Example & $\begin{array}{l}\text { Cohen's } \\
\text { kappa }\end{array}$ & $\mathrm{N}(\%)$ \\
\hline Narrating & $\begin{array}{l}\text { Telling a story about their day, } \\
\text { describing activities }\end{array}$ & $\begin{array}{l}\text { "headed up to the Fox News camera for an } \\
\text { interview" (Rep. Ron Paul, R-TX) }\end{array}$ & 0.83 & $\begin{array}{r}2,069 \\
(7 \%)\end{array}$ \\
\hline Positioning & $\begin{array}{l}\text { Situating one's self in relation to } \\
\text { another politician or political issue, } \\
\text { may be implied rather than explicit }\end{array}$ & $\begin{array}{l}\text { "A9: Theoretically, not realistically. HC } \\
\text { spending is growing 4x inflation and } \\
\text { driving our debt. Let's tackle the real } \\
\text { threat. \#ryanttv" (Rep. Paul Ryan, R-WI) }\end{array}$ & 0.87 & $\begin{array}{l}6,728 \\
(22 \%)\end{array}$ \\
\hline $\begin{array}{l}\text { Directing to } \\
\text { information }\end{array}$ & $\begin{array}{l}\text { Pointing to a resource URL, telling } \\
\text { you where you can get more info }\end{array}$ & $\begin{array}{l}\text { "Harkin Announces More Than } \$ 300,000 \\
\text { for Housing in Tama County } \\
\text { http://1.usa.gov/lf6Aem" (Sen. Tom } \\
\text { Harkin, D-IA) }\end{array}$ & 0.70 & $\begin{array}{r}12,468 \\
(41 \%)\end{array}$ \\
\hline $\begin{array}{l}\text { Requesting } \\
\text { action }\end{array}$ & $\begin{array}{l}\text { Explicitly telling followers to go do } \\
\text { something online or in person (not } \\
\text { just visiting a link but asking them to } \\
\text { do something like sign a petition, } \\
\text { apply, vote) - look for action verbs }\end{array}$ & $\begin{array}{l}\text { "RSVP to my Immigration Forum with } \\
\text { Rep. Luis Gutierrez this Saturday in } \\
\text { Brooklyn http://t.co/qTcWugs" (Rep. } \\
\text { Yvette Clark, D-NY) }\end{array}$ & 0.70 & $\begin{array}{r}299 \\
(1 \%)\end{array}$ \\
\hline Thanking & $\begin{array}{l}\text { Says nice things about or thanks } \\
\text { someone else, e.g. congratulations, } \\
\text { compliments }\end{array}$ & $\begin{array}{l}\text { “@rmartindc Thanks. MoC's handwriting } \\
\text { is probably on par with M.D.'s. Glad I } \\
\text { could make your job easier.” (Rep. John } \\
\text { Shimkus, R-IL) }\end{array}$ & 0.90 & $\begin{array}{r}667 \\
(2 \%)\end{array}$ \\
\hline Other & $\begin{array}{l}\text { Doesn't fit in any other Action } \\
\text { category, or one can't tell what they're } \\
\text { doing }\end{array}$ & $\begin{array}{l}\text { “@jfor441 Will do!” (Rep. Jason Chaffetz, } \\
\text { R-UT) }\end{array}$ & N/A & N/A \\
\hline
\end{tabular}

Table 1. Definitions, Examples, Reliability, and Distribution of Qualitative Action Codes

Earlier work about how Congress users Twitter [20] uses a similar coding scheme - the Golbeck scheme - but provides only percent agreement measures of reliability. Percent agreement is an overly liberal measure of intercoder reliability because it does not account for chance agreement [38]. We originally tried to apply their coding scheme to our larger dataset but were unable to reach acceptable agreement using Cohen's kappa scores. The main problem in applying the Golbeck scheme is the difficulty in determining which tweets do not fall in their information category. We updated Golbeck's [20] scheme in a number of important ways:

- We allowed tweets to fall into multiple categories rather than in mutually exclusive categories. We noticed that many tweets were explicitly accomplishing more than one communication activity (e.g., pointing to a resource and staking a political position). Such multi-purpose tweeting is not uncommon [35]. Though posts are limited to 140 characters, Twitter users are remarkably effective at accomplishing multiple communication activities within a single tweet.
- We distinguished "positioning" from "information" in order to compare communication on Twitter with communication elsewhere, such as websites [54] because we recognize the differences between providing opinions and publicizing resources.

- We refined the "requesting action" category to refer to tweets that demanded effortful activities such as participating in community events rather than low-effort activities such as reading a statement. In other words, we exclude slacktivism activities from "requested actions" when coding tweets. Slacktivism, a shortening of "slacker activism", is used to describe activities that require little effort but still provide activists with a sense of accomplishment or engagement [16]. In our schema, only "active" actions are included in requesting action, allowing us to examine how often public officials encourage their followers to actively engage in the political process or get involved in a social issue. 
- We ignored questions of audience (Golbeck's "communication" codes) because we could not reach agreement on the audiences implied in such short posts.

\section{Automated Classification}

We used the second manually labeled dataset of 526 tweets mentioned in Section 3.1 to reevaluate our coding scheme and to train binary classifiers for each of the following five action codes: narrative, positioning, provide information, request action, and thanks. We did not train classifiers for the code "other," since tweets that are not assigned to one of the other five codes are automatically labeled as "other."

To train and evaluate our classifiers, we used MALLET (Machine Learning for LanguagE Toolkit) [39] and experimented with three supervised learning trainers in order to develop three classifiers: naïve Bayes, decision tree, and maximum entropy. In each case, the words appearing in a tweet are its features, and the classifier is a function that maps the features onto the output classes (i.e., action codes). In other words, we infer the intended action or speech act of the tweeter using only the word frequencies in the respective tweet. For each classifier, we experimented with two representations of the text of the tweets: the raw text and the text with stop words removed. For each classifier, we used MALLET's default English stop words.

The maximum entropy classifier performed best. Maximum entropy models begin with the assumption that uniform distributions are preferred (i.e., assume a 50/50 chance that a tweet is "narrative" or not). They use training data to learn constraints to be applied to this distribution. Nigam and colleagues report that in many cases, maximum entropy outperforms naïve Bayes, however, it does have a tendency toward overfitting in cases where data is sparse (i.e., when there are only few positive examples of a tweet of a given class). The accuracy statistics for our classifier's performance with the training data of 526 tweets are reported in Table 3.

We used supervised trainers, which means that we used a set of tweets labeled for the action code we wanted to predict. The algorithm was then applied to a test set of tweets, and the predicted classification labels were compared to the (manually created) truth data. We conducted a 10-fold cross-validation procedure for each of the six classifiers. For each of 10 iterations, 0.90 of the tweets are randomly assigned to the training set, and 0.10

\begin{tabular}{|lrrrrr|}
\hline Classifier & Narr & Posit & Info & ReqAc & Thank \\
\hline MaxEnt & 0.83 & 0.71 & 0.91 & 0.91 & 0.95 \\
& -0.05 & -0.06 & -0.03 & -0.03 & -0.03 \\
\hline No stop & 0.80 & 0.71 & 0.91 & 0.91 & 0.93 \\
words & -0.07 & -0.07 & -0.04 & -0.03 & -0.04 \\
\hline
\end{tabular}

Table 3. Mean (s.d.) Classification Accuracy on Test Data Using 10-fold Cross-validation Procedure

\begin{tabular}{|lrrrr|}
\hline & N & Median & S.D. & Range \\
\hline Overall & 35,361 & 1,090 & 2,134 & $18-8,893$ \\
By Females & 5,535 & 760 & 873 & $60-3,677$ \\
By Males & 29,826 & 1,155 & 2,262 & $18-8,893$ \\
By Republicans & 21,253 & 1,228 & 2,544 & $51-8,893$ \\
By Democrats & 13,648 & 825 & 799 & $18-3,005$ \\
By Independents & 460 & 3,372 & 0 & 3,372 \\
By Representatives & 28,834 & 1,055 & 2,266 & $18-8,893$ \\
By Senators & 6,527 & 1,219 & 1.396 & $165-5,927$ \\
\hline
\end{tabular}

Table 2. Frequencies of tweets by gender, party, and chamber

of the tweets to the test set. We observed that stop word removal did not help improve performance of the classifiers. This seems to suggest that with texts this short, how tweeters use non-content, functional words may contain useful information.

\section{RESULTS}

\section{General Twitter behavior}

Frequency of tweeting is not normally distributed among members of Congress or within gender, chamber, or party groups (see Table 2). We included all group dummy variables (male, Republican, and Senate) and a "days in office" variable in regression analyses to compare frequency of tweets among groups (see Table 4). Our results show significant main effects for all four variables. Male, Republican, Representative and longer tenure predict more tweeting. Clearly there are other factors that influence frequency of tweets; even when including all four variables, the model explains only $10 \%$ of the variance.

\section{Speech acts on Twitter}

Our analysis of the content of tweets, (see Table 1), shows that providing information is the most common action accomplished in officials' tweets (41\%), followed by positioning (22\%), narrative (7\%), thanking (2\%), and requesting action (1\%).

Many tweets fell into more than one category. For instance, "Unemployment rate is $9.1 \%$. Democrats promised 'stimulus' spending binge would keep it below $8 \%$ http://j.mp/pnaIhs \#wherearethejobs" both positioned the author against the stimulus spending by pointing out a perceived failure and provided additional information by pointing to a URL with more information. Similarly, "I am on live with Drew Skaggs on WLGC talking about the \#debtlimit and our plan to cut spending. Listen in: http:/goo.gl/b62Wi" narrated the author's activities (as a guest on a radio show), his position on economic policy (cutting spending) and provided additional information by including a URL. 


\begin{tabular}{|c|c|c|c|c|}
\hline & Model 1 & Model 2 & Model 3 & Model 4 \\
\hline \multirow[t]{2}{*}{ Male } & $943.309^{* * *}$ & $597.863^{* * *}$ & $593.203 * * *$ & $585.361 * * *$ \\
\hline & $(30.83)$ & $(30.67)$ & $(30.68)$ & $(30.46)$ \\
\hline \multirow[t]{2}{*}{ Republican } & & $1110.179^{* * *}$ & $1105.994 * * *$ & $1201.930 * * *$ \\
\hline & & $(22.76)$ & $(22.78)$ & (22.99) \\
\hline \multirow[t]{2}{*}{ Senate } & & & $-113.932 * * *$ & $-134.147 * * *$ \\
\hline & & & $(28.00)$ & $(27.81)$ \\
\hline \multirow[t]{2}{*}{ Days in Office } & & & & $0.077 * * *$ \\
\hline & & & & $(0.00)$ \\
\hline \multirow[t]{2}{*}{ Constant } & $1080.438^{* * *}$ & $704.562 * * *$ & $732.038 * * *$ & $427.333 * * *$ \\
\hline & $(28.31)$ & (28.47) & $(29.25)$ & $(31.92)$ \\
\hline r2 & 0.026 & 0.087 & 0.088 & 0.101 \\
\hline
\end{tabular}

Table 4. Comparing tweeting frequency across groups

We make three additional observations about the overlaps of Twitter action. First, tweets that provide information often link to news articles, mainly statistics or a world event:

- This@WashingtonPost story is very interesting if true. Iranian lawmaker says Obama proposed talks... http://t.co/8n6YbZmI (Rep. Paul Gosar, R$\mathrm{AZ})$

- The Bureau of Labor Statistics reports today that the US economy added 200,000 jobs in Dec. Unemployment falls to $8.5 \%$. http://t.co/WHZO7RaR (Rep. Andre Carson, DIN)

Second, officials often used narrative tweets to mention a TV or Radio appearance:

- I'm talking to CNN's@ @randikayecnn at $1: 15 \mathrm{pm}$ ET and MSNBC's@mitchellreports at 1:45pm ET"please tune in! \#nhprimary \#FITN (Rep. Debbie Wasserman Schultz, D-FL)

Third, many of the position tweets had a very partisan tone, placing blame or accusing the other party or president:

- President Obama is again bypassing Congress-this time to give amnesty to an untold number of illegal immigrants- http://t.co/KhqoQBCQ (Rep. Walter Jones, R-NC)

- House Republicans refused to let me speak on House floor today. GOP needs to return to work on \#payrolltaxcut. Video: http://t.co/YwZFxwWb (Rep. Jim Moran, D-VA)
Because we are specifically examining politicians, we distinguish between tweets about political positions and tweets about general information. Making this distinction between informative tweets and positioning tweets likely accounts for the marked decline in the proportion of information tweets we observed compared to Golbeck's earlier reports [20].

\section{DISCUSSION}

\section{Comparing behavior among groups}

Gender, Party, Chamber, and Tenure

Our results indicate that a member's gender, party affiliation, chamber, and tenure in Congress all have strong effects on his/her frequency of tweeting. We see large variance in tweeting frequency in all groups, though (see Table 2). Women in Congress are often cast as quite distinct from men in Congress [e.g., 3,40], but research on members' web sites revealed that these stereotypes did not hold. Rather, our findings confirm existing research that women can be just as explicit about their engagement in power struggles and in the diversity of issues about which they care [44]. Our current analysis does not allow us to explore whether women engage in different communication actions than men, but we did identify a significant difference in the volume of their communication - in Congress, women are decidedly less active on Twitter than are men. Instead,

As social media becomes an increasingly significant source of political news, the dominance of male voices becomes more problematic. Our results suggest that Republicans, Representatives, and men dominate most of the conversation, and future work will examine the implications of these imbalances. 


\section{Illustrative example tweeters}

We noticed differences between the distributions of actions in our training sample and the larger sample, most notably decreases in narrating and positioning. We expect that the users whose tweets we used to develop our coding scheme, those most and least active on Twitter, differ in their actions from other users. It's possible that users around the median for participation are using Twitter more conversationally. However, when we compare prolific and minimally active tweeters ${ }^{2}$, we see similar patterns of action. Table 5 and Figure $1^{3}$ show that among minimally active tweeters (Reps. Alexander and Biggert), providing information remains the most common action, followed by positioning. Prolific tweeters (Reps. Issa and Ross) exhibit similar patterns, yet moderately active tweeters' (Reps. Cravaack and Ros-Lehtinen) patterns are different. Rep. Cravaack accomplished positioning more often than providing informatiWhile Rep. Ros-Lehtinen shows an even greater contrast between the rates of positioning and providing information: Rep. Cravaack tweeted positions only slightly more often than information. We do not claim to generalize statistically from this sample of six, rather we leverage these users to illustrate some of the differences suggested by our large-scale analysis.

\section{Tweet Content}

Our content analysis results (summarized in the last column of Table 1) differ somewhat from earlier results on the content of Congress's tweets [20, 53]: we found a lower proportion of information tweets and identified a specific type of politically charged tweet action. Some of the differences between earlier results and ours can be explained by differences in coding schemes. Though the absolute proportions of Congress's activities on Twitter have changed over time, the relative proportions have not. For instance, though earlier work predicted that as adoption increased, behaviors would change [19], we confirmed that providing information is the most common action, followed by policy or position tweets.

Public officials use Twitter in campaigning [21, 53, 54] and rely on web-based media for a variety of communication activities including "issue dialogue" and "position taking" [54]. Distinguishing between positioning and providing information allows us to compare the tweets to other forms of communication such as candidate websites. We found that, even though they were not engaged in explicit public campaigning activities during our study period, members of Congress often used Twitter to publicly position themselves. According to Xenos and Foot [54], this kind of public position, a hallmark of traditional offline

\footnotetext{
${ }^{2}$ In an effort to minimize variability among our example tweeters, we use only Republican members of the House in this section.

${ }^{3}$ We excluded requesting action in Figure 1 because none of these six example users tweeted requesting action.
}

\begin{tabular}{|lrrr|}
\hline Official & Tweets & Followers & Friends \\
\hline $\begin{array}{l}\text { Rep. Rodney Alexander } \\
\text { (R-LA) }\end{array}$ & 18 & 1319 & 171 \\
$\begin{array}{l}\text { Rep. Judy Biggert (R- } \\
\text { IL) }\end{array}$ & 26 & 5514 & 224 \\
$\begin{array}{l}\text { Rep. Chip Cravaack (R- } \\
\text { MN) }\end{array}$ & 253 & 2377 & 1246 \\
$\begin{array}{l}\text { Rep. Ileana Ros- } \\
\text { Lehtinen (R-FL) }\end{array}$ & 312 & 9235 & 10 \\
$\begin{array}{l}\text { Rep. Dennis Ross (R- } \\
\text { FL) }\end{array}$ & 976 & 3648 & 1114 \\
Rep. Darrell Issa (R- & 1208 & 36,819 & 22,524 \\
CA) & & & \\
\hline
\end{tabular}

Table 5 Numbers of Tweets, Followers, and Friends for Examples of Minimally Active, Moderately Active and Prolific Tweeters

campaigning, is common in campaign websites. Our results indicate that position taking is common on Twitter as well, suggesting that candidates are using Twitter to implicitly campaign throughout their tenure. While perhaps not surprising, this finding is interesting because it indicates that public officials do not alter their communication strategies between media but rather use a common strategy across media (e.g., websites, speeches, Twitter). Given the remarkable differences between the audience, length of content, frequency of updates, and reach among various media, a single strategy for all is surprising.

What effects do current events have on Congress's Twitter behavior?

A number of events that occurred during our sample's timeframe may have impacted our results. During part of

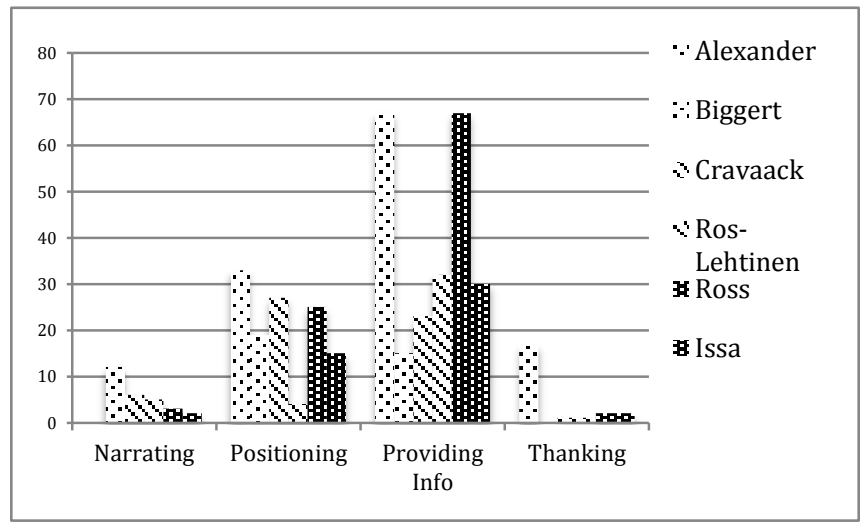

Figure 1. Comparing actions between prolific and minimally active tweeters. Tweeters are arranged left to right from least active to most active. The $\mathbf{Y}$-axis indicates the percentage of a users' tweets that were assigned a given action by the automatic classifier. Users are grouped into three pairs minimally active, moderately active, and prolific - indicated by the fill patterns within the bars. 
this period, Congress was in winter recess, and some research suggests they behave quite differently when not in session [19]. Other events that happened between December 2011 and February 2012 and may have influenced what Congress tweeted about include budget debates, SOPA and PIPA, the first caucuses and primaries, and Gabrielle Giffords stepping down.

Some officials even took to Twitter to talk about Twitter itself during the SOPA and PIPA debates. These conversations provided a number of interesting examples of positioning tweets, and the wide public debate about these bills may have produced more positioning tweets than we would have seen in another sample. For instance, Rep. Joe Walsh (R - IL) voiced his opposition: "Thank God twitter isn't blocked today so I can tell you that I refuse to vote for \#SOPA. \#uncensored \#StopSOPA". Rep. Lynn Westmoreland (R - GA) and Rep. Louise Slaughter (D NY), respectively, voiced theirs as well and acknowledged hearing from their constituents: "Getting lots of calls on \#SOPA and \#PIPA. I oppose both bills because of their unintended consequences. http://t.co/ngjLiMQp" and "To clarify, I oppose both \#SOPA and \#PIPA. The many tweets you've sent me today are the best proof that these bills should be stopped". While on the side that supported the legislation, Rep. Darrell Issa (R - CA) posted "Got some great news for you...we've just released \#PIPA in the Madison platform at http://t.co/lkiF4nOB: http://t.co/Rteeze7L \#SOPA \#OPEN."

\section{What isn't Congress doing on Twitter?}

What Congress is not doing via social media is also interesting. For example, very few tweets requested action. Our results indicate that public officials rarely (only 352 of 30,373 tweets) request that their followers actively engage. Earlier research suggests great promise for social media in increasing civic engagement [55], but our results suggest it is as best underutilized and at worst not used at all.

It seems Congress uses social media as a broadcast forum rather than as an engagement tool. Much of the conversation about the role of social media in political communication revolves around transparency [6-8, 30] and civic engagement $[11,55]$, but we saw no evidence of Congress using Twitter to increase either transparency or engagement. Of course, the scale of Twitter activity among officials implicitly creates transparency, especially when officials reveal their daily activities through narrating (e.g., "The H.R. 3630 Conference Committee just concluded our first meeting. Read my opening remarks here: http://t.co/ByceoXM1" [Rep. Tom Price, R - GA]) or providing information about floor ("On my way to the House Floor to discuss the rise in poverty in America. We need \#jobs. Pass HR 3638 - Restore American Dream for 99\% Act" [Rep. Barbara Lee, D - CA]) and media appearances ("I'll be discussing the dangers of Rx drug abuse on CNNw/@Soledad_OBrien tomorrow at 8 a.m. EST. I hope you'll tune in." [Rep. Mary Bono Mack, R $\mathrm{CA}$ ). Officials often point their followers to results of votes and committee meetings ("Here's the roll call for the Call of the House, also known as the quorum call. Quorum calls officially are used... http://t.co/XsEpESjN" - [Rep. Justin Amash, $\mathrm{R}-\mathrm{MI}]$ ), but the potential to increase transparency via social media remains.

We also see relatively few narrative tweets. Of course, the rules governing how Congress may use social media ${ }^{4}$ and websites limit the kinds of communication they attempt, and so the prevalence of providing information is not surprising. Similarly, the lack of narrative among public officials' may be because rules prohibit communications that are not germane to the official and representational duties. However, just as most Twitter users do, even members of Congress use Twitter to share mundane details of their activities: "I just got up to 663 in \#DoodleJump!!! Beat that!" (Sen. John McCain, R - AZ).

\section{FUTURE WORK}

Our results suggest a number of interesting avenues for future work. For instance, we are not able to discuss what positions public officials take or whether they discuss only a few key issues online. Additionally, the limited time of our data collection prevented us from making comparisons longitudinally or between campaign season and regular, off-season governance.

Our data will allow us to explore relationships among the various kinds of measurable activities. For instance, we will be able to determine whether the level of twitter activity influences the kinds of actions officials accomplish - e.g., are frequent tweeters more likely to use positioning statements while infrequent tweets mainly provide information? As our examples show, different distributions of action appear across different levels of activity, and this point must be addressed in future analyses.

Our results raise questions about the relationship between pro-social actions such as thanking and potentially alienating actions such as positioning. Some previous research has examined the concepts of "civility" and "politeness" in online political discussions [40, 43, 46], and future work should examine officials' language more closely in order to better understand the relationship between language and behavior. Specifically, we predict that pro-social language is a good predictor of political centrism, and we intend to include this measure in later regressions to test the predictive power of a civility scale. Those regressions will be the main focus of our next stage of research during which we will test the predictive power of social media behavior, namely that an official's social media behavior can be used to predict his offline behavior such as voting and communication strategy. In this way, we can examine theories of political communication related to agenda setting [41], market segmentation of political

\footnotetext{
${ }^{4} \mathrm{http}: / /$ democrats.cha.house.gov/official-social-media-andsecondary-web-sites
} 
messages [42], and shifting communication vehicles over time $[9,10,31]$. Looking even farther ahead, this can be the basis for later tests of motivated reasoning by examining citizens who follow high-tweeting members of Congress.

We excluded retweets from our automated results because they present unique coding challenges. Retweets are repeated, unoriginal content, and the lack of variance makes it difficult to compare them to original content. For instance, we cannot assume that a retweet constitutes an endorsement of the original tweet. In fact, some officials make it clear that not all retweets are endorsements by including a disclaimer in their Twitter profiles. Officials' retweeting and modified tweeting behaviors remain to be examined in order to determine officials' intentions when reusing others' content.

The social activity trail officials leave by using Twitter is also ripe for study. For instance, officials' conversation networks may reveal their connections with other officials, appointees, the public, lobbyists, etc. Using social network analysis to examine Twitter relationships and behaviors is increasingly common [4, 12, 51, 52], and our future work will explore public officials' social media networks.

\section{CONCLUSION}

As Twitter becomes a more common means for officials to communicate with their constituents, it becomes more important that we understand just how that communication relates to other political activities and what kinds of communication are accomplished via social media. Our findings indicate that officials frequently use Twitter to advertise their political positions and to provide information but rarely to request political action from their constituents or to recognize the good work of others. Congress appears to use Twitter as yet another broadcast mechanism rather than as a way to engage in dialogue with the public or as a "call to action" to organize constituents. Though Twitter and its use are often cast as "social computing," among Congress, the "social" is less pronounced than we expected.

Future work will examine the relationships between the networks created through Twitter activity and political coalitions, and among the language used and the governing behaviors. 2012 offers a unique opportunity to examine campaigning behavior in order to compare campaign communication and social interaction with everyday governance. Ours is not the first study to examine Twitter use by the U.S. Congress, but we do offer an essential update based on a larger, more inclusive dataset, robust coding scheme, and comparisons among groups of MOCs. We have provided additional groundwork for future research examining the behavior of public officials online and its impacts on the relationship between public officials and their constituencies.

\section{ACKNOWLEDGEMENTS}

This material is based on work supported by the Illinois Institute of Technology (IIT) Social Networks Research Group and the IIT Graduate College.

\section{REFERENCES}

1. Adamic, L.A. and Glance, N. 2005. The political blogosphere and the 2004 U.S. election: Divided they blog. Proc. LinkKDD '05, 36-43.

2. Austin, J.L. 1962. How to do things with words. Oxford University Press.

3. Bach, K. 1998. Speech acts. Routledge Encyclopedia of Philosophy. E. Craig, ed. Routledge.

4. Bakshy, E. et al. 2011. Everyone's an influencer: Quantifying influence on Twitter. Proc. WSDM '11, 65-74.

5. Berkman, M.B. and O'Connor, R.E. 1993. Do Women Legislators Matter?: Female Legislators and State Abortion Policy. American Politics Research. 21, 1, 102-124.

6. Bertot, J. 2010. Using ICTs to create a culture of transparency: E-government and social media as openness and anti-corruption tools for societies. Government Information Quarterly. 27, 3, 264-271.

7. Bertot, J. and Jaeger, P. 2010. Social media technology and government transparency. Computer. 43, 11, 5359.

8. Bertot, J.C. et al. 2010. Crowd-sourcing transparency: ICTs, social media, and government transparency initiatives. Proceedings of the 11th Annual International Digital Government Research Conference on Public Administration Online: Challenges and Opportunities.

9. Bimber, B. 2003. Information and American democracy: Technology in the evolution of political power. Cambridge University Press.

10. Blumler, J.G. and Kavanagh, D. 1999. The Third Age of political communication: influences and features. Political Communication. 16, 3, 209-230.

11. Campbell, S.W. and Kwak, N. 2011. Political involvement in "mobilized" society: The interactive relationships among mobile communication, network characteristics, and political participation. Journal of Communication. 61, 6, 1005-1024.

12. Cha, M. et al. 2010. Measuring user influence in twitter: The million follower fallacy. Proc. ICWSM '10, 10-17.

13. Cohen, J. 1960. A coefficient of agreement for nominal scales. Educational and Psychological Measurement. 20, 1, 37-46.

14. Diakopoulos, N. and Shamma, D. 2010. Characterizing debate performance via aggregated Twitter sentiment. Proc. CHI '10, 1195-1198.

15. Druckman, J.N. et al. 2010. Issue engagement on congressional candidate web sites, 2002-2006. Social Science Computer Review. 28, 1, 3-23.

16. Gaffney, D. 2010. \#iranElection: Quantifying online activism. Proc. WebScilo. 
17. Garber, M. 2012. A year after the Egyptian revolution, $10 \%$ of its social media documentation is already gone. The Atlantic.

18. Gilmore, J. 2012. Ditching the pack: Digital media in the 2010 Brazilian congressional campaigns. New Media \& Society. 14, 4, 617-633.

19. Glassman, M.E. et al. 2009. Social networking and constituent communication: Member use of Twitter during a two-week period in the 111th Congress (Report No. R40823).

20. Golbeck, J. et al. 2010. Twitter use by the U.S. Congress. Journal of the American Society for Information Science and Technology. 61, 8, 16121621.

21. Graf, J. 2008. New media-The cutting edge of campaign communications. Campaigns on the Cutting Edge. R. Semiatin, ed. CQ Press. 48-68.

22. Green, A. 2011. Twitter database server (Beta 0.10), http://140dev.com/free-twitter-api-source-codelibrary/twitter-database-server/.

23. Groeling, T. 2010. When Politicians Attack: Party Cohesion in the Media. Cambridge University Press.

24. Gulati, G.J. and Williams, C.B. 2007. Closing the gap, raising the bar: Candidate web site communication in the 2006 campaigns for congress. Social Science Computer Review. 25, 4, 443-465.

25. Hemphill, L. 2011. Twitter-collectors (144e2f0f6), https://github.com/casmlab/Twitter-collectors.

26. Hemphill, L. and Otterbacher, J. 2012. Learning the lingo? Gender, prestige and linguistic adaptation in review communities. Proc. CSCW'12, 305-314.

27. Herring, S.C. 2003. Gender and power in online communication. The Handbook of Language and Gender. J. Holmes and M. Meyerhoff, eds. Blackwell Publishers. 202-228.

28. Howard, P.N. 2005. New media campaigns and the managed citizen. Cambridge University Press.

29. Hsu, C. and Park, H.W. 2012. Mapping online social networks of Korean politicians. Government Information Quarterly. 29, 2, 169-181.

30. Jaeger, P.T. and Bertot, J.C. 2010. Transparency and technological change: Ensuring equal and sustained public access to government information. Government Information Quarterly. 27, 4, 371-376.

31. Jenkins, H. 2006. Convergence culture. New York University Press.

32. Kim, M. and Park, H.W. 2012. Measuring Twitterbased political participation and deliberation in the South Korean context by using social network and Triple Helix indicators. Scientometrics. 90, 1, 121140.

33. Klotz, R. 2007. Internet campaigning for grassroots and astroturf support. Social Science Computer Review. 25, 1, 3-12.

34. Krippendorff, K. 2004. Reliability in Content Analysis. Human Communication Research. 30, 3, 411-433.
35. Kwak, H. et al. 2010. What is Twitter, a social network or a news media? Categories and subject descriptors. Proc. $W W W$ '10, 591-600.

36. Lam, S.K. et al. 2011. WP: Clubhouse? An exploration of Wikipedia's gender imbalance. Proc. WikiSym '11, $1-10$.

37. Livne, A. et al. 2011. The party is over here: Structure and content in the 2010 election. Proc. ICWSM ' 11 .

38. Lombard, M. et al. 2002. Content Analysis in Mass Communication: Assessment and Reporting of Intercoder Reliability. Human Communication Research. 28, 4, 587-604.

39. McCallum, A.K. 2002. MALLET: A maching learning for language toolkit, http://mallet.cs.umass.edu/.

40. McClain, C. 2009. Debating restrictions on embryonic stem cell research. Politics and the Life Sciences: The Journal of the Association for Politics and the Life Sciences. 28, 2 , 48-68.

41. McCombs, M. 2004. Setting the agenda: The mass media and public opinion. Polity Press.

42. Mullainathan, S. and Shleifer, A. 2005. The market for news. American Economic Review. 95, 4, 1031-1053.

43. Ng, E.W.J. and Detenber, B.H. 2006. The impact of synchronicity and civility in online political discussions on perceptions and intentions to participate. Journal of Computer-Mediated Communication. 10, 3.

44. Niven, D. and Zilber, J. 2001. Do Women and Men in Congress Cultivate Different Images? Evidence from Congressional Web Sites. Political Communication. 18, 4, 395-405.

45. Noveck, B.S. 2011. What's in a name? Open gov and good gov. Huffington Post.

46. Papacharissi, Z. 2004. Democracy online: Civility, politeness, and the democratic potential of online political discussion groups. New Media \& Society. 6, 2, 259-283.

47. Schneider, S.M. and Foot, K.A. 2006. Web campaigning by U.S. presidential primary candidates in 2000 and 2004. The Internet Election: Perspectives on the Web's Role in Campaign 2004. A. Williams and J. Tedesco, eds. Rowman \& Littlefield. 21-36.

48. Shamma, D. et al. 2009. Tweet the debates: Understanding community annotation of uncollected sources. Proc. ICWSM '09.

49. Southall, A. 2012. White House ethics hub goes live online. New York Times.

50. Trammell, K.D. et al. 2006. Evolution of Online Campaigning: Increasing Interactivity in Candidate Web Sites and Blogs Through Text and Technical Features. Mass Communication and Society. 9, 1, 2144.

51. Tumasjan, A. et al. 2011. Election forecasts with Twitter: How 140 characters reflect the political landscape. Social Science Computer Review. 29, 4, 402-418. 
52. Weng, J. et al. 2010. TwitterRank: Finding topicsensitive influential Twitterers. Proc. WSDM '10, 261 -270 .

53. Williams, C.B. and Gulati, G.J. 2011. Communicating with constituents in 140 characters or less: Twitter and the diffusion of technology innovation in the United States Congress. SSRN, http://ssrn.com/paper=1817053.
54. Xenos, M.A. and Foot, K.A. 2005. Politics as usual, or politics unusual? Position taking and dialogue on campaign websites in the 2002 U.S. Elections. Journal of Communication. 55, 1, 169-185.

55. Xenos, M.A. and Moy, P. 2007. Direct and differential effects of the internet on political and civic engagement. Journal of Communication. 57, 4, 704718. 